\title{
BMJ Open Investigating self-perceived health and quality of life: a longitudinal prospective study among beginner recreational exercisers in a fitness club setting
}

\author{
Hege Heiestad (D), Christina Gjestvang (D) , Lene A H Haakstad (D)
}

To cite: Heiestad $\mathrm{H}$, Gjestvang C, Haakstad LAH. Investigating self-perceived health and quality of life: a longitudinal prospective study among beginner recreational exercisers in a fitness club setting. BMJ Open 2020;10:e036250. doi:10.1136/ bmjopen-2019-036250

- Prepublication history for this paper is available online. To view these files, please visit the journal online (http://dx.doi. org/10.1136/bmjopen-2019036250).

Received 11 December 2019 Revised 24 April 2020 Accepted 27 April 2020

\section{Check for updates}

(c) Author(s) (or their employer(s)) 2020. Re-use permitted under CC BY-NC. No commercial re-use. See rights and permissions. Published by BMJ.

Department of Sports Medicine, Norwegian School of Sports Sciences, Oslo, Norway

Correspondence to Hege Heiestad;

hege.heiestad@nih.no

\section{ABSTRACT}

Objectives This study investigated self-perception of overall health (SPH) and quality of life (QoL) at onset and after 3,6 and 12 months of fitness club membership. Also, we compared SPH and QoL between those who reported regular use of the fitness club ( $\geq 2$ exercise sessions/ week the last month) with those who did not (one exercise session/week or no exercise the last month).

Design Longitudinal prospective study.

Setting 25 fitness clubs in 0slo, Norway.

Participants In total, 250 newly registered fitness club members (equal numbers of men and women, mean age $=36.4 \pm 11.3$ years, mean body mass index $=25.7 \pm 4.4)$ were recruited. At onset $(n=250)$, after $3(n=224)$, $6(n=213)$ and 12 months $(n=187)$, the participants answered an electronic questionnaire, covering background variables, exercise involvement, perceived $\mathrm{SPH}$ and QoL.

Outcome measures SPH was measured by a single-item question, rating health status from poor to excellent on a 5-point scale. High SPH was dichotomised as excellent or good, and low SPH as moderate, fair or poor. QoL was measured on a 7-item scale, rating five statements and dichotomised according to a total max sum score of 35 , with low QoL $\leq 25$ and high QoL $>25$.

Results Repeated measurements did not show any changes in SPH. In QoL, we observed an improvement in QoL sum score and a significant increase in mean scores for two out of five statements at 12 months follow-up: 'In most ways, my life is close to my ideal' $(p=0.036)$ and 'If I could live my life over, I would change almost nothing' $(p<0.001)$. Regular use of the fitness club was associated with high SPH (OR 3.532 (95\% Cl 1.60-7.82), $\mathrm{p}=0.002)$ and high QoL (0R $1.914(95 \% \mathrm{Cl} 0.95-3.86)$, $\mathrm{p}=0.069$ ). The results were unchanged after adjusting for confounders.

Conclusion Regular attendance at a fitness club was associated with high SPH and high QoL at 12 months follow-up.

\section{INTRODUCTION}

Physical activity is a complex behaviour influenced by several different determinants. ${ }^{1}$ Much research has focused on the main
Strengths and limitations of this study

- The use of prospective study design with 12 months follow-up.

- Valid and reliable measurement methods.

- The use of an electronic questionnaire based on previously validated surveys.

Self-reported attendance at the fitness club.

factors that may lead to regular exercise or dropout. There is consensus that enjoyment (intrinsic motives), social support and access to exercise facilities (environmental factors) may positively influence exercise behaviour. On the other side, lack of time and motivation (internal barriers) may inhibit exercise adherence. $^{2}$

According to the WHO, ${ }^{3}$ health is not only the absence of somatic disease but also includes mental and social well-being, putting emphasis on the usefulness and need for investigating individuals' self-perception of overall health $(\mathrm{SPH})$. Up to date, several studies have shown that low SPH may be a valid and robust predictor of morbidity and mortality of various diseases, such as cancer, cardiovascular disease, stress, diabetes and other chronic health conditions. ${ }^{4-7}$ Low SPH is as well associated with being sick-listed and frequent use of healthcare services. ${ }^{8}{ }^{9}$ In different patient groups and among the elderly population, SPH has widely been used to evaluate the effect of healthcare programmes. ${ }^{10}$ The measure is a single-item question, including rating of health status from poor to excellent on a 5-point scale, and as such popular for its simplicity and cost-effectiveness. ${ }^{11}$

It is growing interest in the assessment of physical activity on modification of SPH, and studies have indicated a strong association 
between insufficient physical activity and lower SPH in adults, especially in older individuals. ${ }^{12}{ }^{13}$ However, it is important to investigate SPH not only between individuals that are active or inactive according to current physical activity recommendations ${ }^{14}$ but also if this differs between activity contexts (organised sports clubs, public spaces and fitness clubs) and exercise involvement (frequency, duration, intensity and modes)..$^{15}$

Quality of life (QoL) has also become an important measurement because it is a meaningful indicator of both mental and physical well-being, ${ }^{16}{ }^{17}$ and its positive association with physical activity has been consistently reported in the systematic reviews and meta-analyses. ${ }^{18} 19$ Although there are limited data, it is suggested that QoL may be a key motivator for regular physical activity and exercise,${ }^{20}$ meaning that individuals start and continue to be active because this contributes to their QoL. However, cross-sectional data preclude a conclusion regarding the nature of this association. ${ }^{21}$

Throughout the 1990s, a new venue for physical activity and exercise gradually grew in popularity, the fitness clubs. Worldwide, the fitness club industry has about 183 million members and counts more than 210000 clubs. $^{22}$ Those who join a fitness club may be initially motivated to exercise; still, previous studies have shown a high dropout rate after only 3 months. ${ }^{23}{ }^{24}$ This shows that maintaining regular exercise can be challenging even for motivated individuals. Even though this arena has become a large and growing venue for activity, the scientific knowledge of those that choose to be a member is scant. Research has not yet investigated how fitness club membership relates to SPH and QoL status among beginner recreational exercisers. Hence, the primary aim of the present study was to report longitudinal data of SPH and QoL in an agediverse group of men and women across the first year of fitness club membership. Second, we wanted to examine if SPH and QoL differed between those who reported regular use of the fitness club ( $\geq 2$ exercise sessions/week the last month) with those who did not (one exercise session/week or no exercise the last month).

\section{MATERIALS AND METHODS}

\section{Study design and population}

This is a secondary analysis of data collected as part of the research project 'Fitness clubs-a venue for public health?', ${ }^{24-27}$ a longitudinal prospective study, aiming to investigate which factors influence exercise adherence in beginner recreational exercisers.

The procedures were financed and conducted at the Norwegian School of Sport Sciences (NSSS) (October 2015 to November 2018). No economic compensation was given to the participants.

New members at 25 fitness clubs in Oslo, Norway, were contacted by an email invitation. At first contact, the aims and implications of the study were explained, and the eligibility criteria checked. Enrolment was limited to adults ( $\geq 18$ years), $<4$ weeks membership, healthy (no disease considered to hinder physical activity, eg, severe heart disease or hypertension) and physically inactive (exercising $<60 \mathrm{~min}$ /week at a moderate or vigorous intensity or brisk walking $<150 \mathrm{~min} /$ week, the last 6 months). ${ }^{1428}$

Sample size considerations for SPH and QoL were done together with a professor in biostatistics at NSSS, based on findings in other studies. ${ }^{29-31}$ When an individual starts exercising, it may be that small changes occur in QoL, such as going from 23 (low QoL) to 26 (high QoL) on the total sum score for QoL (35 points). It was estimated that with 70 participants, we would be able to detect a $10 \%$ change in QoL over a 1-year follow-up period. Similarly, with a power of $80 \%$ at the 0.05 level, we would be able to identify small changes in $\mathrm{SPH}$, such as going from three to four on the 5-point Likert scale, with 93 participants. To account for loss to follow-up and be able to do subgroup analyses, we aimed to recruit all individuals who fulfilled the eligibility criteria. In total, 676 fitness club members wanted to participate in the study. We excluded those who already exercised regularly $(n=270)$ or had cardiovascular disease, hypertension or asthma $(n=8)$. Besides, 148 individuals did not respond after the first email, leaving 250 enrolling in the study (figure 1).

\section{Patient and public involvement}

Four volunteers completed a pilot test of the whole electronic questionnaire, which led to minor changes in wording and format. Otherwise, participants and the public have not been involved in the development of research questions, study design or recruitment.

\section{Data collection and measurements}

A standardised electronic questionnaire was answered at onset and after 3, 6 and 12 months of fitness club membership. A pretest of the questionnaire was conducted by four members in the research group, as well as four volunteers. The final questionnaire contained 52 questions at onset and 65 questions at 3, 6 and 12 months. At all time-points, the questionnaire took approximately $30 \mathrm{~min}$ to complete and was answered electronically.

SPH was assessed by answering a global single question: 'In general, how would you rate your health today?' The response options were ranked from 1 to 5 , with the following description: excellent, good, moderate, fair and poor. According to these five levels, we also divided the participants into two categories: high SPH (excellent and good) and low SPH (moderate, fair and poor) to investigate the association between SPH and exercise behaviour, an approach adopted by other researchers. ${ }^{32} 33$

QoL was measured by a Norwegian version of the Satisfaction of Life Scale (SWLS). ${ }^{34}$

Because of multiple assessment points, and a comprehensive questionnaire covering several factors influencing exercise adherence, ${ }^{24-27}$ we decided after discussion in the project group to use SWLS. The SWLS is short and includes five statements only. Several studies have also supported the validity and reliability of the scale. ${ }^{35-38} \mathrm{QoL}$ is measured on a 7-item scale, where the participants rate 
Enrolment

Responded to e-mail invitation $(\mathrm{n}=676)$

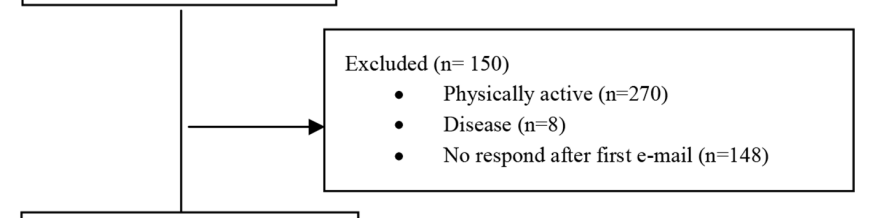

Included $(\mathrm{n}=250)$

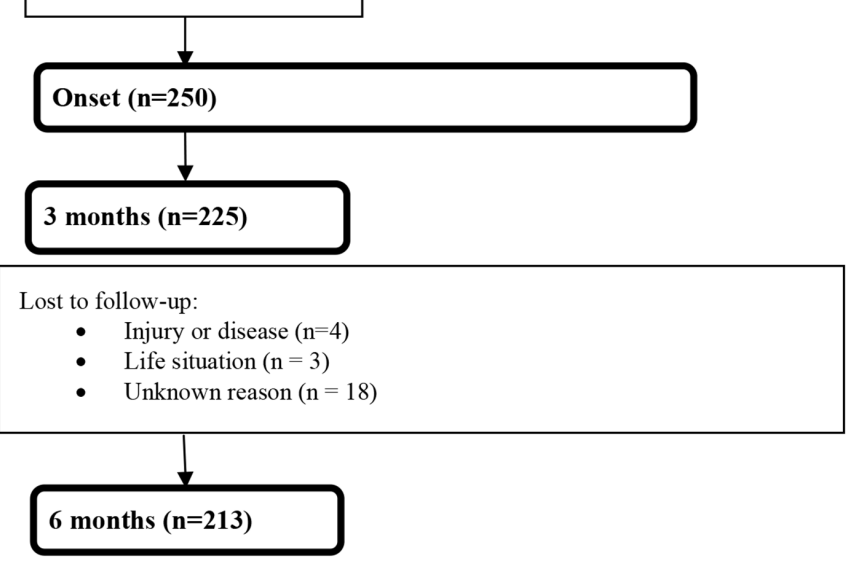

Lost to follow-up:

- Life situation $(\mathrm{n}=2)$

- Unknown reason $(\mathrm{n}=10)$

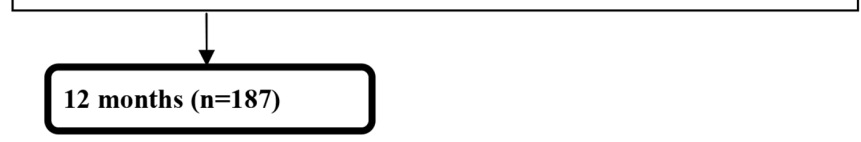

Lost to follow-up:

- Injury or disease $(n=6)$

- Life situation $(\mathrm{n}=11)$

- Unknown reason $(\mathrm{n}=9)$

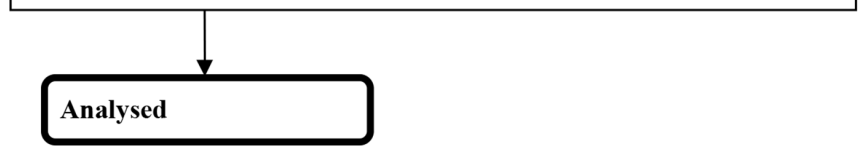

- At onset $(\mathrm{n}=250)$

- At 3 months $(n=225)$

- At 6 months $(\mathrm{n}=213)$

- At 12 months ( $\mathrm{n}=187)$

- Completed testing at all time points $(n=184)$

Figure 1 Flow chart of the participants throughout the data collection.

five different statements from 'strongly disagree' $=1$ to 'strongly agree'=7:

1. 'In most ways, my life is close to my ideal'.

2. 'The conditions of my life are excellent'.

3. 'I am satisfied with my life'.

4. 'So far I have gotten the important things I want in life'.

5. 'If I could live my life over, I would change almost nothing'.
The results from QoL were analysed separately for each statement and as a sum score, ${ }^{31}$ 39-41 and we also dichotomised QoL into two main groups: low QoL (scores 5-25) and high QoL (scores 26-35).

To examine the role of regular exercise on SPH and QoL, we asked the participants to report exercise involvement at the fitness club in the last 4 weeks: (1) 'Have you been a member?': 'yes' or 'no'; (2) Have you been exercising regularly?': 'yes' or 'no'; (3) How often have you exercised per week on average??' 'once a week', 'twice a week', 'three times a week', 'four times a week', 'five times a week', 'six times a week' or 'seven times a week or more'. In line with Garber et $a l^{14}{ }^{14}$ non-regular use was defined as exercising one session/week, or no exercise the last month, whereas regular use of the fitness club was defined as exercising $\geq 2$ times a week. Hence, membership dropouts were counted in the non-regular users of the gym.

Information related to demographic variables and socioeconomic status was obtained from the questionnaire answered at onset, covering age, gender, body weight, level of education, total household income, cohabitation, children and occupation.

\section{Statistical analyses}

SPSS V.25.0 for Windows was used for statistical analysis. Data are presented as numbers with percentages or means with SDs, as well as OR with $95 \%$ CIs and $\mathrm{p}$ values.

Chronbach's $\alpha$ for the SWLS was $0.87,0.91,0.90$ and 0.91 at baseline, and after 3, 6 and 12 months, respectively. $\chi^{2}$ analysis was used to compare categorical variables and two-sided independent sample t-test for continuous variables (table 1). In addition, McNemars test, Cochran's $Q$ paired sample t-test and one-way repeated measures analysis of variance were used to analyse changes in SPH and QoL. Data (tables 2 and 3) are reported for participants who completed the questionnaire at onset of fitness club membership $(n=250), 3$ months $(n=224), 6$ months $(n=213)$ and 12 months $(n=187)$, whereas $p$ values are shown for participants that completed the questionnaire at all measurement points only $(n=184)$. Also, due to the ethics of mandatory questionnaire responses, we included 'I do not want to answer' or 'Not relevant' as response options, which in the SPSS data set were treated as missing values, so individual questions may have varying response rates.

To assess the difference between those who reported regular use of the fitness club $(n=70)$ with those who did not $(n=93)$ on SPH and QoL, we included prospective data obtained at 12 months (table 4). Based on previous literature ${ }^{42-44}$ and crude analysis comparing demographic and health factors between high and low SPH, and high and low QoL, seven variables (exercise, age, cohabitation, total household income, body mass index (BMI), children and gender) with $\mathrm{p}$ values $\leq 0.05$ (table 1 ) were all entered in the above order in the adjusted model (table 5).

\section{RESULTS}

General characteristics of all participants at onset of fitness club membership, divided into high and low SPH 
Table 1 General characteristics of the participants at onset of fitness club membership, divided into high and low SPH and QoL $(n=250)$

\begin{tabular}{|c|c|c|c|c|c|c|c|}
\hline Background variable & $\begin{array}{l}\text { All } \\
(n=250)\end{array}$ & $\begin{array}{l}\text { SPH } \\
\text { high (n=166) }\end{array}$ & $\begin{array}{l}\text { SPH low } \\
(n=83)\end{array}$ & $P$ value & $\begin{array}{l}\text { QoL } \\
\text { high } \\
(n=88)\end{array}$ & $\begin{array}{l}\text { QoL low } \\
(n=161)\end{array}$ & $P$ value \\
\hline Norwegian descent, n (\%) & $196(78.4)$ & $134(80.7)$ & $62(74.7)$ & 0.630 & 65 (73.9) & $130(80.7)$ & 0.428 \\
\hline Gender: men, n (\%) & $125(50.0)$ & $83(50.0)$ & $42(50.6)$ & 1.000 & 36 (40.9) & 89 (55.3) & 0.042 \\
\hline Age (years), mean (SD) & $36.4(11.3)$ & $34.5(10.5)$ & $40.1(11.9)$ & $<0.001$ & $38.5(12.1)$ & $35.2(10.6)$ & 0.027 \\
\hline Age $\geq 40$ years, $n(\%)$ & 81 & 43 & 37 & 0.010 & 33 & 47 & 0.230 \\
\hline BMI, mean (SD) & $25.7(4.4)$ & $25.2(4.0)$ & $26.6(5.0)$ & 0.017 & $25.3(4.1)$ & $25.9(4.5)$ & 0.263 \\
\hline $\mathrm{BMI} \geq 25$ (overweight or obese), $\mathrm{n}(\%)$ & $121(48.4)$ & $72(43.4)$ & $48(57.8)$ & 0.044 & $36(40.9)$ & $85(52.8)$ & 0.097 \\
\hline $\begin{array}{l}\text { Education level: } \\
\text { university } \geq 4 \text { years, } n \text { (\%) }\end{array}$ & $102(40.8)$ & $66(39.8)$ & $36(44.4)$ & & $40(45.5)$ & $61(37.9)$ & 0.304 \\
\hline $\begin{array}{l}\text { Total household income: } \\
\text { High >US\$87 } 500 \\
\text {, n (\%) }\end{array}$ & $114(45.6)$ & $74(47.4)$ & $40(51.3)$ & & $51(62.2)$ & $62(40.8)$ & 0.003 \\
\hline Living with a partner, n (\%) & $153(61.2)$ & $102(61.4)$ & $50(60.2)$ & 0.963 & $70(79.5)$ & $82(50.9)$ & $<0.001$ \\
\hline Children, n (\%) & $80(32)$ & $50(31.1)$ & 29 (34.9) & 0.531 & $36(40.9)$ & $44(27.3)$ & 0.040 \\
\hline Employed outside of home, $n(\%)$ & $185(74.0)$ & $120(72.3)$ & $64(77.1)$ & 0.134 & $63(71.6)$ & $122(75.8)$ & 0.142 \\
\hline
\end{tabular}

BMI, body mass index; QoL, quality of life; SPH, self-perception of overall health.

and QoL, are shown in table 1. In total, $66.4 \%$ and $35.2 \%$ rated their SPH and QoL as high, respectively. There were no gender differences concerning SPH, but more women $(41.9 \%)$ than men $(28.8 \%)$ rated their QoL as high. The high SPH group had lower age and mean BMI and fewer were overweight or obese compared with the low SPH group. Participants with high QoL had higher age and were more likely to report high total household income, living with a partner and having children than the low QoL group (table 1).

At onset, more men than women had a household income $\geq$ US $\$ 87500(52.0 \%$ vs $39.2 \%)$, worked outside the home $(86.4 \%$ vs $61.6 \%)$, were overweight or obese (BMI $\geq 25 \mathrm{~kg} / \mathrm{m}^{2}, 58.4 \%$ vs $38.7 \%$ ) and older (38.5 vs 34.3 years). More details of the study participants have been published previously. ${ }^{22-25}$ Throughout the initial year of fitness club membership, we found no changes in SPH (table 2).

In QoL measurements, we observed an increase in mean scores for all five statements, a significant increase in two out of five statements: 'In most ways, my life is close to my ideal' ( $\mathrm{p}=0.036)$ and 'If I could live my life over, I would change almost nothing' $(\mathrm{p}<0.001)$, and also an improvement in sum score $(\mathrm{p}=0.071)$ (table 3$)$.

At all measurements, regular use of the fitness club was associated with high SPH, as well as higher sum scores on QoL at 12 months follow-up (table 4). There was a large drop in participants reporting regular use of the fitness

Table 2 SPH at onset, 3, 6 and 12 months of fitness club membership

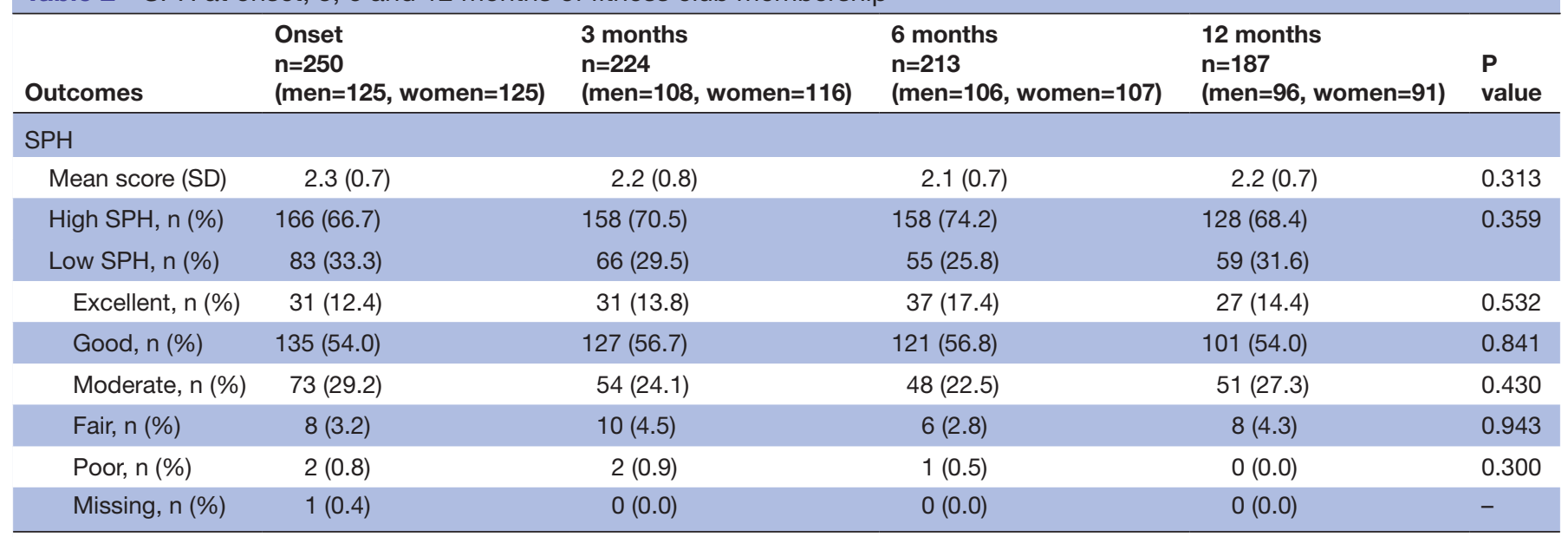

Results are shown in mean (SD) or $n(\%)$. $P$ values are shown for participants that completed the questionnaire at all measurement points $(n=184)$. $\mathrm{SPH}$, self-perception of overall health. 
Table 3 QoL at onset, 3, 6 and 12 months of fitness club membership

\begin{tabular}{|c|c|c|c|c|c|}
\hline Outcomes & $\begin{array}{l}\text { Onset } \\
n=250 \\
(m e n=125, \\
\text { women=125) }\end{array}$ & $\begin{array}{l}3 \text { months } \\
n=224 \\
(m e n=108, \\
\text { women=116) }\end{array}$ & $\begin{array}{l}6 \text { months } \\
\mathrm{n}=213 \\
\text { (men=106, } \\
\text { women=107) }\end{array}$ & $\begin{array}{l}12 \text { months } \\
n=187 \\
\text { (men=96, } \\
\text { women=91) }\end{array}$ & $P$ value \\
\hline Sum score QoL, mean (SD) & $22.2(6.7)$ & $22.2(7.1)$ & $22.5(6.9)$ & $23.2(6.8)$ & 0.071 \\
\hline High QoL, n (\%) & $88(35.3)$ & $76(34.2)$ & $79(37.1)$ & $76(41.1)$ & 0.263 \\
\hline $\begin{array}{l}\text { 'The conditions of my life are } \\
\text { excellent', mean (SD) }\end{array}$ & $4.7(1.5)$ & $4.7(1.5)$ & $4.7(1.5)$ & $4.8(1.5)$ & 0.356 \\
\hline 'I am satisfied with my life’, mean (SD) & $4.9(1.6)$ & $4.8(1.6)$ & $4.9(1.5)$ & $5.0(1.5)$ & 0.216 \\
\hline
\end{tabular}

Results are shown in mean (SD) or $\mathrm{n}(\%)$. $\mathrm{P}$ value is shown for participants that completed the questionnaire at all measurement points $(\mathrm{n}=184)$. QoL, quality of life.

club ( $\geq 2$ times a week) from $3(51.8 \%)$ to $6(37.6 \%)$ and $12(37.4 \%)$ months $(\mathrm{p}=0.003)$, with no gender or age differences. More details of exercise behaviour at the gym are previously reported. ${ }^{21-24}$

Also after adjusting for confounders (age, cohabitation, total household income, BMI, children and gender), regular use of the fitness club $\geq 2$ times weekly was associated with reporting high SPH (OR 3.532 (95\% CI 1.607.82), $\mathrm{p}=0.002$ ) and QoL (OR 1.914 (95\% CI 0.95-3.86), $\mathrm{p}=0.069)($ table 5$)$.

To evaluate if the participants were representative of our initial study population, a comparison analysis was performed with the 63 participants lost to follow-up at 12 months. Mean scores at onset were 2.3 \pm 0.7 (all) and $2.4 \pm 0.9$ (lost to follow-up) and 22.2 \pm 6.7 (all) and 21.4 \pm 6.5 (lost to follow-up) for SPH and QoL, respectively. No differences were found in demographic and socioeconomic variables (data not shown).

\section{DISCUSSION}

To our knowledge, this is the first study that has investigated SPH and QoL among beginner recreational exercisers in a fitness club setting. The main findings were

Table 4 SPH and QoL compared in participants reporting regular and non-regular use at a fitness centre at 3, 6 and 12 months

\begin{tabular}{|c|c|c|c|c|c|c|c|c|c|}
\hline & \multicolumn{3}{|l|}{3 months } & \multicolumn{3}{|l|}{6 months } & \multicolumn{3}{|l|}{12 months } \\
\hline & $\begin{array}{l}\text { Regular use } \\
(n=116)\end{array}$ & $\begin{array}{l}\text { Non-regular } \\
\text { use }(n=106)\end{array}$ & $P$ value & $\begin{array}{l}\text { Regular } \\
\text { use }(n=80)\end{array}$ & $\begin{array}{l}\text { Non-regular } \\
\text { use }(n=125)\end{array}$ & $P$ value & $\begin{array}{l}\text { Regular } \\
\text { use }(n=70)\end{array}$ & $\begin{array}{l}\text { Non-regular } \\
\text { use }(n=93)\end{array}$ & $P$ value \\
\hline Mean score (SD) & $2.1(0.7)$ & $2.4(0.8)$ & 0.001 & $1.9(0.7)$ & $2.3(0.8)$ & 0.001 & $1.9(0.7)$ & $2.4(0.7)$ & $<0.001$ \\
\hline High SPH, n (\%) & $91(78.4)$ & $67(63.2)$ & 0.018 & $67(83.8)$ & $85(68.0)$ & 0.015 & $59(84.3)$ & $57(61.3)$ & 0.002 \\
\hline $\begin{array}{l}\text { Sum score QoL, } \\
\text { mean (SD) }\end{array}$ & $22.5(6)$ & $21.8(7.6)$ & 0.469 & $22.6(7.2)$ & $22.5(6.8)$ & 0.954 & $25.1(5.5)$ & $22.0(7.0)$ & 0.002 \\
\hline High QoL, n (\%) & $39(34.2)$ & $36(34.0)$ & 1.000 & $35(43.8)$ & $42(33.6)$ & 0.177 & $34(49.3)$ & $34(36.6)$ & 0.144 \\
\hline Low QoL, n (\%) & $75(65.8)$ & $70(66.0)$ & & $45(56.2)$ & $83(66.4)$ & & $35(50.7)$ & $59(63.4)$ & \\
\hline
\end{tabular}

Results are shown in mean (SD) or $n(\%)$. Participants not reporting regular use of the fitness club were $n=2, n=8$ and $n=24$ at 3,6 and 12 months, respectively.

QoL, quality of life; SPH, self-perception of overall health. 
Table 5 The association between use of a fitness club and high SPH/QoL at 12 months, controlled for age, cohabitation, total household income, BMI, children and gender



BMI, body mass index; QoL, quality of life; SPH, self-perception of overall health.

an increase in mean scores for all five statements in QoL, even if only two of the statements reached statistical significance. We also found an improvement in QoL sum score throughout the 1-year follow-up period. No changes were observed for SPH during the initial year of fitness club membership. Regular fitness club users rated SPH higher at all measurement points, as well as perceived their QoL higher than non-regular users at 12 months follow-up.

We found no changes in SPH throughout the follow-up period, which is contrary to another study investigating SPH among healthy adults. ${ }^{5}$ One explanation to this may be that more than half of the participants $(66.7 \%)$ in our study rated their SPH as high already at onset of fitness club membership, which caused less opportunity for further improvement. Also, very few (4\%) rated their SPH fair or poor at onset. As such, the ceiling effect in SPH might be a cause for our results. Previous research on the association between exercise and SPH have primarily been done among sick or elderly populations, reporting that regular physical activity and even a small dose of regular exercise (defined as engaging in activities more than once a week, in line with our definition of regular use of the gym) may improve SPH. ${ }^{45} 46$

Precise definitions of QoL are scant and measures vary greatly. ${ }^{18}$ Still, research including systematic reviews and meta-analysis has suggested that regular exercise may enhance QoL and contributes to emotional wellbeing. ${ }^{18} 19$ This is consistent with the present study, where regular exercise at the fitness club was associated with higher scores in perceived QoL. Our data also give some support for a dose-response curve and a threshold of at least twice weekly to achieve benefits in $\mathrm{SPH}$ and QoL. However, we cannot conclude that exercise contributes to QoL or if it is the other way around. We found, however, that QoL score increased from onset of membership to 12 months follow-up, lending credibility to the hypothesis that improvement in QoL might be a key motivator for sustained exercise. ${ }^{47}$ However, social and cognitive factors (such as social interactions while exercising, group cohesion and self-efficacy) may confound the association between regular use of a fitness club and QoL. In line with others, we believe that these factors might have a mediating role rather than being real confounding factors. ${ }^{47} 48$ Throughout the follow-up period, there was an increase in two out of five statements of QoL and an improvement in the total sum score. The three non-significant statements could be explained by a higher rating already at onset and a possible ceiling effect, which we also discussed earlier regarding SPH. Besides, the SWLS focuses to a large extent on how the participants feel and think with respect to several important aspects from a lifelong perspective (from birth and up to date). Hence, it can be difficult to rationalise our results and the influence of joining a fitness club, whatever the findings.

\section{Participants}

More than $60 \%$ of the participants did not manage to visit the fitness club regularly after 6 and 12 months of the initial year of membership. Others have also reported a high dropout rate $(50 \%)$ from regular use of the fitness club within the first 6 to 12 months of membership. ${ }^{49} 50$ A retrospective study found that only $10 \%$ of fitness club members reported regular gym attendance (at least four visits monthly) after 6 months. ${ }^{51}$ In our study, this number was higher. Nevertheless, this shows that maintaining an active lifestyle can be challenging even for motivated individuals, and it highlights the need to develop strategies and interventions to facilitate exercise behaviour in a fitness club setting. It may be useful to understand that regular exercise can contribute to increased SPH and QoL. Finding time is vital if regular use is to be adhered to. Even though most fitness clubs are located where people live and travel, have flexible opening hours, many also offering childcare, former physically inactive individuals may have had problems getting into a weekly routine. ${ }^{52}$ 


\section{Outcomes}

Both SPH and QoL were measured by a standardised electronic questionnaire at all time-points. The use of an electronic questionnaire based on previously validated surveys made it easy to gather responses quickly and eliminate the costs associated with printing and distributing paper-based questionnaires. Self-report is inexpensive, takes up little time to conduct and is practical. Anyway, due to social desirability, the risk of over-reporting may be high. For instance, individuals may report more socially acceptable answers rather than being honest and may interpret the wording of questions differently. ${ }^{53}$ However, assessment of SPH and QoL depends on the individual, subjective perception. Hence, self-report may be an appropriate measurement method for measuring $\mathrm{SPH}$ and QoL.

SPH was assessed by answering a global single question used in numerous other studies, and subjective assessment of health has been found to highly correlate with results of its objective assessment and health status indices. ${ }^{54}$ QoL was measured by a Norwegian version of SWLS, which is considered to be a reliable and valid instrument and has been widely used to examine the subjective QoL of people experiencing different health concerns. ${ }^{30} 40$

\section{Strengths and limitations}

A strength of the present study was the use of prospective study design with 12 months follow-up. Also, the inclusion of data concerning personal health behaviours (BMI and exercise) and demographics (age, cohabitation, total household income, having children) is considered strengths. Hence, we were able to adjust for these factors in the analyses. All participants were untrained at study enrolment and may as such be considered representative for new members at fitness clubs, ${ }^{27}$ as well as comparable with the general adult population. ${ }^{55}$ There was an equal number of men and women and we used valid and reliable measurement methods. ${ }^{30}$ Despite a high dropout from the study itself, we had a sufficient number of participants at all measurement points regarding a priory power calculation for SPH and QoL.

Limitations were that the investigation was carried out in Norwegian only, excluding participants from other ethnic groups, as well as that attendance at the fitness club was self-reported. Studies are consistent in showing that individuals tend to overestimate what they do. ${ }^{56}$ Nevertheless, if this was the case, the results of the present study provide a conservative calculation of exercise involvement at the fitness club. The questionnaire took approximately $30 \mathrm{~min}$ to complete and was answered electronically. Such a time-consuming questionnaire might cause more loss to follow-up. Further, participation was voluntary, and it may be possible that the data contain a certain level of volunteer bias, questioning the representativeness of the results.

\section{CONCLUSION}

We found an increase in all five statements in QoL, while only two of the items reached statistical significance.
We also found an improvement in the QoL sum score, whereas no changes were observed in SPH during the first year of fitness club membership. Our results add to the literature that regular attendance at the fitness club after 12 months was associated with a high SPH and QoL.

Acknowledgements The authors thank Ingar Holme and Morten Fagerland, professors in biostatistics, Norwegian School of Sports Sciences, for guidance with power considerations and statistical analysis.

Contributors $\mathrm{HH}$ outlined the manuscript. CG plotted all data and developed the questionnaire together with LAHH. CG and LAHH were responsible for data collection and recruited the participants. HH, CG and LAHH did the testing. LAHH originated the idea for the present study and supervised the project. All authors participated in discussing the design of the study, read and corrected draft versions of the manuscript and approved the final manuscript.

Funding The project was financed by and conducted at the Norwegian School of Sports Sciences.

Competing interests None declared.

Patient and public involvement Patients and/or the public were involved in the design, or conduct, or reporting, or dissemination plans of this research. Refer to the Methods section for further details.

\section{Patient consent for publication Not required.}

Ethics approval The project was reviewed by the Regional Committee for Medical and Health Research Ethics (REK 2015/1443 A), who concluded that, according to the act on medical and health research (the Health Research Act 2008), the study did not require full review by REK. The project was approved by the Norwegian Social Science Data Service (NSD 44135). The procedures followed the World Medical Association Declaration of Helsinki.

Provenance and peer review Not commissioned; externally peer reviewed.

Data availability statement Data are available in a public, open access repository. All data are fully available without restriction. Data are from the 'Physical activity at fitness clubs. -A venue for public health'-study whose authors may be contacted at the Norwegian School of Sports Sciences. hege.heiestad@nih.no.

Open access This is an open access article distributed in accordance with the Creative Commons Attribution Non Commercial (CC BY-NC 4.0) license, which permits others to distribute, remix, adapt, build upon this work non-commercially, and license their derivative works on different terms, provided the original work is properly cited, appropriate credit is given, any changes made indicated, and the use is non-commercial. See: http://creativecommons.org/licenses/by-nc/4.0/.

\section{ORCID iDs}

Hege Heiestad http://orcid.org/0000-0003-4127-0878

Christina Gjestvang http://orcid.org/0000-0003-2253-1921

Lene A H Haakstad http://orcid.org/0000-0002-8153-7410

\section{REFERENCES}

1 Choi J, Lee M, Lee J-K, et al. Correlates associated with participation in physical activity among adults: a systematic review of reviews and update. BMC Public Health 2017;17:356.

2 Teixeira PJ, Carraça EV, Markland D, et al. Exercise, physical activity, and self-determination theory: a systematic review. Int J Behav Nutr Phys Act 2012;9:78.

3 World Health Organization. Basic documents. World Health Organization, 2014.

4 Falconer J, Quesnel-Vallée A. Pathway from poor self-rated health to mortality: explanatory power of disease diagnosis. Soc Sci Med 2017;190:227-36.

5 Bamia C, Orfanos P, Juerges $\mathrm{H}$, et al. Self-Rated health and all-cause and cause-specific mortality of older adults: individual data metaanalysis of prospective cohort studies in the chances Consortium. Maturitas 2017;103:37-44.

6 Barger SD, Cribbet MR, Muldoon MF. Participant-Reported health status predicts cardiovascular and all-cause mortality independent of established and nontraditional biomarkers: evidence from a representative US sample. J Am Heart Assoc 2016;5:e003741.

7 Bopp M, Braun J, Gutzwiller F, et al. Health risk or resource? gradual and independent association between self-rated health and mortality persists over 30 years. PLoS One 2012;7:e30795. 
8 Vingård $\mathrm{E}$, Alexanderson $\mathrm{K}$, Norlund $\mathrm{A}$. Chapter 9. consequences of being on sick leave. Scand J Public Health 2004;32:207-15.

9 Miilunpalo S, Vuori I, Oja P, et al. Self-Rated health status as a health measure: the predictive value of self-reported health status on the use of physician services and on mortality in the working-age population. J Clin Epidemiol 1997;50:517-28.

10 Chodzko-Zajko WJ, Proctor DN, Fiatarone Singh MA, et al. Exercise and physical activity for older adults. Med Sci Sports Exerc 2009;41:1510-30.

11 World Health Organization. Health interview surveys: towards international harmonization of methods and instruments. Vol. 58. Copenhagen, Denmark: World Health Organization Regional Office for Europe, 1996.

12 Lee $Y$. The predictive value of self assessed general, physical, and mental health on functional decline and mortality in older adults. $J$ Epidemiol Community Health 2000;54:123-9.

13 Lera-Lopez F, Ollo-López A, Garrués-Irisarri M, et al. How the relationship between physical activity and health changes with age. Eur J Ageing 2019;16:3-15.

14 Garber CE, Blissmer B, Deschenes MR, et al. American College of sports medicine position stand. quantity and quality of exercise for developing and maintaining cardiorespiratory, musculoskeletal, and neuromotor fitness in apparently healthy adults: guidance for prescribing exercise. Med Sci Sports Exerc 2011;43:1334-59.

15 Weinberg RS, Gould D. Foundations of sport and exercise psychology. 7edn. Human Kinetics, 2018: 423-33.

16 Gill DL, Hammond CC, Reifsteck EJ, et al. Physical activity and quality of life. J Prev Med Public Health 2013;46 Suppl 1:S28-34.

17 Awick EA, Ehlers DK, Aguiñaga S, et al. Effects of a randomized exercise trial on physical activity, psychological distress and quality of life in older adults. Gen Hosp Psychiatry 2017:49:44-50.

18 Gillison FB, Skevington SM, Sato A, et al. The effects of exercise interventions on quality of life in clinical and healthy populations; a meta-analysis. Soc Sci Med 2009;68:1700-10.

19 Bize R, Johnson JA, Plotnikoff RC. Physical activity level and healthrelated quality of life in the general adult population: a systematic review. Prev Med 2007;45:401-15.

20 Gill DL, Hammond CC, Reifsteck EJ, et al. Physical activity and quality of life. J Prev Med Public Health 2013;46 Suppl 1:S28

21 Cherry K. Cross-sectional research method: How does it work. Advantages and challenges. Student Resources, 2018. Available: https://www. verywellmind. com/cross-sectional-research-howdoes-it-work

22 IHRSA Global Report. The IHRSA global report 2019, 2019.

23 Sperandei S, Vieira MC, Reis AC. Adherence to physical activity in an unsupervised setting: explanatory variables for high attrition rates among fitness center members. J Sci Med Sport 2016;19:916-20.

24 Gjestvang C, Stensrud T, Haakstad LAH. Are changes in physical fitness, body composition and weight associated with exercise attendance and dropout among fitness Club members? longitudinal prospective study. BMJ Open 2019;9:e027987.

25 Gjestvang C, Stensrud T, Haakstad LAH. How is rating of perceived capacity related to $\mathrm{VO}$ and what is $\mathrm{VO}_{\text {an }}$ at onset of training? BMJ Open Sport Exerc Med 2017;3:e000232.

26 Gjestvang C, Stensrud T, Hansen BH, et al. Are fitness Club members more likely to meet physical activity guidelines than the general adult population? Med Sci Sports Exerc 2019;51:835.

27 Haakstad LA, Gjestvang C, Lamerton T, et al. Urinary incontinence in a fitness Club setting - is it a workout problem? Int Urogynecol J 2020;25:1-8.

28 Hawley-Hague $\mathrm{H}$, Horne M, Skelton DA, et al. Review of how we should define (and measure) adherence in studies examining older adults' participation in exercise classes. BMJ Open 2016;6:e011560.

29 Doblhammer G, GumJ. A demographic perspective on gender, family and health in Europe. Springer International Publishing., 2018.

30 Pavot W, Diener E. Review of the satisfaction with life scale. In: Assessing well-being. Dordrecht: Springer, 2009: 101-17.

31 Corrigan JD, Kolakowsky-Hayner S, Wright J, et al. The satisfaction with life scale. J Head Trauma Rehabil 2013;28:489-91.

32 Machón M, Vergara I, Dorronsoro M, et al. Self-Perceived health in functionally independent older people: associated factors. BMC Geriatr 2016;16:66.

33 Girón P. Is age associated with self-rated health among older people in Spain? Cent Eur J Public Health 2012;20:185-90.

34 Diener E, Emmons RA, Larsen RJ, et al. The satisfaction with life scale. J Pers Assess 1985;49:71-5.
35 Pavot W, Diener E. The satisfaction with life scale and the emerging construct of life satisfaction. J Posit Psychol 2008;3:137-52.

36 Tessier P, Blanchin M, Sébille V. Does the relationship between health-related quality of life and subjective well-being change over time? An exploratory study among breast cancer patients. Soc Sci Med 2017;174:96-103

37 Pavot W, Diener E, Colvin CR, et al. Further validation of the satisfaction with life scale: evidence for the cross-method convergence of well-being measures. J Pers Assess 1991;57:149-61.

38 Jovanović V, Lazić M, Gavrilov-Jerković V. Measuring life satisfaction among psychiatric patients: measurement invariance and validity of the satisfaction with life scale. Clin Psychol Psychother 2020:cpp.2434.

39 Kobau R, Sniezek J, Zack MM, et al. Well-Being assessment: an evaluation of well-being scales for public health and population estimates of well-being among US adults. Appl Psychol 2010;2:272-97.

40 Clench-Aas J, Nes RB, Dalgard OS, et al. Dimensionality and measurement invariance in the satisfaction with life scale in Norway. Qual Life Res 2011;20:1307-17.

41 Vittersø J. Satisfaction with life scale. Tidsskrift for norsk psykologiforening 2009;46:757-8.

42 Ogbeide SA, Neumann CA, Sandoval BE, et al. Gender differences between body weight and psychological well-being during young adulthood: a brief report. The New School Psychology Bulletin 2010;8:41-6.

43 Pino-Domínguez L, Navarro-Gil P, González-Vélez AE, et al. SelfPerceived health status, gender, and work status. J Women Aging 2016;28:386-94.

44 eurostat statistics-explained. Self-Perceived health statistics. Available: https://ec.europa.eu/eurostat/statistics-explained/index. php/Self-perceived_health_statistics

45 Bherer L, Erickson Kl, Liu-Ambrose T. A review of the effects of physical activity and exercise on cognitive and brain functions in older adults. J Aging Res 2013;2013:657508

46 Chapman SB, Aslan S, Spence JS, et al. Shorter term aerobic exercise improves brain, cognition, and cardiovascular fitness in aging. Front Aging Neurosci 2013;5:75.

47 Segar ML, Eccles JS, Richardson CR. Rebranding exercise: closing the gap between values and behavior. Int J Behav Nutr Phys Act 2011;8:94.

48 Young MD, Plotnikoff RC, Collins CE, et al. Social cognitive theory and physical activity: a systematic review and meta-analysis. Obes Rev 2014;15:983-95.

49 Rustaden AM, Haakstad LAH, Paulsen G, et al. Effects of BodyPump and resistance training with and without a personal trainer on muscle strength and body composition in overweight and obese women-A randomised controlled trial. Obes Res Clin Pract 2017;11:728-39.

50 Middelkamp J, van Rooijen M, Wolfhagen P, et al. The effects of a self-efficacy intervention on exercise behavior of fitness Club members in 52 weeks and long-term relationships of Transtheoretical model constructs. J Sports Sci Med 2017;16:163-71.

51 Middelkamp J, Van Rooijen M, Steenbergen B. Attendance behavior of ex-members in fitness clubs: a retrospective study applying the stages of change. Percept Mot Skills 2016;122:350-9.

52 Mâsse LC, Nigg CR, Basen-Engquist K, et al. Understanding the mechanism of physical activity behavior change: challenges and a call for action. Psychol Sport Exerc 2011;12:1-6.

53 Kaleta D, Makowiec-Dabrowska T, Dziankowska-Zaborszczyk E, et al. Physical activity and self-perceived health status. Int J Occup Med Environ Health 2006;19:61-9.

54 Caputo A. Social desirability bias in self-reported well-being measures: evidence from an online survey. Universitas Psychologica 2017:16:245-55.

55 Dumith SC, Hallal PC, Reis RS, et al. Worldwide prevalence of physical inactivity and its association with human development index in 76 countries. Prev Med 2011:53:24-8.

56 Sallis JF, Saelens BE. Assessment of physical activity by self-report: status, limitations, and future directions. Res Q Exerc Sport 2000;71 Suppl 2:1-14.

57 Schaller A, Rudolf K, Dejonghe L, et al. Influencing factors on the overestimation of self-reported physical activity: a cross-sectional analysis of low back pain patients and healthy controls. Biomed Res Int 2016;2016:1497213 